\section{A Consumer Horticulture Computer Network for Extension Agents}

\author{
Diane Relf ${ }^{1}$, Ellen Silva ${ }^{2}$, and \\ Virginia Nathan ${ }^{2}$
}

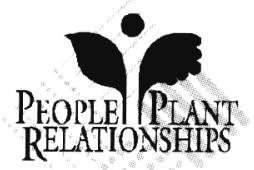

Additional index words. mass media materials, information transfer, electronic communications technology

Summary. In 1985 an extension consumer horticulture computer information system (HORT) was initiated on the Virginia Tech mainframe computer to mitigate the demands on agents' time while providing monthly professional updates and accurate, timely information for use in their local programs. Agents access the information through their office microcomputers, which are linked to the Virginia Tech mainframe computer. Agents can transfer the needed information onto a diskette for reference, immediate use, or further editing or print a hard copy on campus to be mailed to them. Slide sets or videotapes can be ordered from the Virginia Tech Learning Resource Center (LRC) on this system. The monthly releases are available at no charge to anyone in the land-grant system with a BITNET or Internet user identification number.

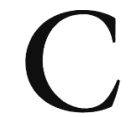
omputer networks are an effective means of providing extension agents and the public with timely information to support their educational programs. The Clemson Univ. Forestry and Agricultural Network (CUFAN) is a statewide network of interconnected computers and terminals linked to a central database at the university (DeWitt, 1988) and is available to the public at minimal cost. The Pennsylvania Extension Network (PEN) offers access to a computer-based library from the College of Agriculture directly to the residents of the state at no charge. Spartan Ornamental Network (SON) is a subscription service from Michigan State University and focuses exclusively on horticultural information (Bufford, 1991). At Virginia Tech University a network was developed specifically to support the agents in their programming in the area of consumer horticulture. The network is based in the mainframe on the campus and can be accessed by staff in all of the extension offices in the state.

When the mainframe is accessed, the agent types in "HORT," and the main directory appears (Fig. 1). Descriptions of the component categories and evaluations of their utility follow below.

The Virginia Gardener monthly releases. Each month consumer horticulture information files are developed and transferred onto the HORT program as timely information for 2 months in the future. Having this amount of lead time allows agents flexibility in accessing the information they

${ }^{7}$ Associate Professor, Dept. of Horticulture. Virginia Polytechnic Institute and State Univ., Blacksburg, VA 24061-0327.

${ }^{2}$ Extension Technician, Dept. of Horticulture. need, taking into consideration climatic variations across the state and work schedule differences. Each month's copy is $>10,000$ words. The files accessible in this category are updated monthly and include: The Virginia Gardener Question Box, approximately seven pages of gardening questions and answers, applicable to the season but not divided by length or subject area; The Virginia Gardener Press Releases, six press releases $\approx 500$ words long, of which one covers a specific insect and one addresses a nutrient, pesticide, or yard waste management issue for improved environmental quality; The Virginia Gardener Monthly Notes, a compilation of 50 or more timely gardening tips; The Virginia Gardener Research Abstracts, an explanation of the importance to the consumer of five current research articles, and summaries of the research methods used. All of the monthly releases since 1986 are retained chronologically in files that can be accessed by year, month or category.

A search program has been written to search all files or selected categories of files for key words or word combinations. This is a relatively expensive procedure, particularly if conducted via long-distance telephone lines. However, once identified, the articles can be accessed directly from this program and downloaded to the microcomputer or printed.

The Virginia Gardener extension publications. Selection of this category allows the agent to use a micro-

\section{Consumer Horticulture Index}

Moving the cursor to an application and pressing Enter activates the program. Moving the cursor to a file and pressing Return allows you to view the file contents. (Press F1 for further information on this program.)

$>$ THE VIRGINIA GARDENER MONTHLY RELEASES

> THE VIRGINIA GARDENER EXTENSION PUBLICATIONS

$>$ THE VIRGINIA GARDENER SLIDE/VIDEO LOAN LIBRARY

$>$ PLANT FACT SHEETS

$>$ THE VIRGINIA GARDENER MASS MEDIA PROGRAMS

$>$ MASTER GARDENER INFORMATION

$>$ 4-H HORTICULTURE

$>$ ENVIRONMENTAL ISSUES AND THE HOME GARDEN

$>$ HORTICULTURE THERAPY

$>$ HUMAN ISSUES IN HORTICULTURE

F1 Help F3 Exit HORT F7 Backward F2 Next Category F4 CmdLine F8 Forward F10 Main Menu 
computer to access the list of 42 extension publications available electronically. This index provides the publication title and number for reference and ordering. By positioning the computer cursor on the desired publication and pressing the "Enter" key, the agent can view the full-text. The entire publication can be printed in the local office, downloaded to the agent's microcomputer for modification, electronically mailed to another agent, or ordered in quantity from the Extension Distribution Center at Virginia Tech.

Tbe Virginia Gardener slide/video loan library. This electronic catalog indexes the residential horticulture slide sets and videotapes available from Virginia Tech's Learning Resource Center. The slide set index includes the title of the set, the number of slides in each of the 102 sets, and the source from which the set was obtained (if other than Virginia Tech). An individual set can be chosen, and the full text of the slide presentation script can be viewed, printed, downloaded, or electronically mailed. The videotape index provides a list of available tapes with running times and lecturers' credentials. By positioning the computer cursor on the desired videotape and pressing the "Enter" key, agents can access an abstract and an outline of the presentation. Agents also can view ordering instructions and can request slides or videos to be shipped to their local office.

There are other categories that can be accessed by agents using the unit office microcomputer in the manner previously described. These include:

Plant fact sheets. Originally developed as printouts for two horticulture interactive video programs, there are 131 fact sheets on cut flowers, foliage, and houseplants and 141 on landscape plants (trees, shrubs, vines, and ground covers). The content of each fact sheet may be transferred electronically.

The Virginia Gardener mass media programs. Information is provided on accessing those elements of the Virginia Gardener program that originate on the Virginia Tech campus and serve clientele directly. Each of these programs is produced under the title The Virginia Gardener and consists of a monthly subscription newsletter, a weekly radio program, and a weekly newspaper column. Information also is provided on using the computer garden-planning service available through the Virginia Tech mainframe and on the Extension Public Information Systems Kiosks in 15 malls and libraries across the state that provide horticultural information through interactive video programs.

Master Gardener information. This category includes a list of Master Gardener final exam questions, indexed according to the subjects covered in the Virginia Master Gardener Handbook, for use by agents in developing local exams; the Virginia Master Gardener Newsletter; audiovisual and publication resources; and Master Gardener policies and procedures (including the state association bylaws).

4-H horticulture. Resources, audiovisual materials, and publications to support 4-H and youth gardening programs are provided.

Environmental issues and the home garden. This category provides lists ofpublications, slide sets, videotapes, and other resources for fertilizer, pesticide, and yard-waste management education programs aimed at improving water quality and reducing waste going to landfills.

Horticultural therapy. Agents can access six articles on various aspects of horticultural therapy that were pub- lished in journals and which ordinarily would not be available for agent use in program development.

Human issues in horticulture. Nine papers relevant to the application of horticulture to human life-quality are available electronically in this category.

System benefits. This system provides significant financial and personnel savings. The Office of Consumer Horticulture no longer needs to send paper copies of information to local extension units. This reduces duplication, postage, and personnel costs. Because the information can be transferred in electronic form, the amount of clerical time spent retyping material in the local office should be negligible.

Before it is made available, the subject matter is reviewed for accuracy by appropriate experts, reducing the extension agent's preparation time, while increasing reliability.

Most of the information in the system can be used by agents in developing mass media presentations. The Virginia Gardener monthly releases are ready for immediate use in mass media programming or can be localized by the agent. Other information, such as that in the extension publications and slide set scripts, may need. to be reduced in volume or edited to support specific topics.

Any of the information can be incorporated and reorganized into forms tailored to specific lectures or workshops, or can be printed to provide an immediate reply to correspondence.

Evaluation of monthly releases. In order to determine how useful the monthly Virginia Gardener releases are to the local agents, a survey was mailed to all unit offices in May 1988. Agents in 73 of the 107 unit offices (68\%) reported using the HORT system.

The agents accessed the materials in a variety of ways, with some using two or more methods; $24.7 \%$ of the users electronically downloaded the files to a diskette, $63.0 \%$ printed a hard copy, and $45.2 \%$ accessed the mainframe files repeatedly as needed. The low use of the downloading function $(24.7 \%)$, which saves phone charges by immediately transferring the files from the Virginia Tech mainframe to the office microcomputer, indicates the agents' lack of familiarity with this new technology. The $32 \%$ of the extension offices not using the program is attributed primarily to the slow acceptance of computer technology. However, part of it reflects the unwillingness of some traditionally agricultural agents to provide horticultural information to their clientele. As more agents and Master Gardeners understand and use this resource, there should be additional time savings.

Agents report that using the Virginia Gardener monthly releases results in a statewide savings in preparation time of $180 \mathrm{~h} \cdot$ week $^{-1}$-the equivalent of 4.5 full-time extension agents. A total savings in clerical time of $105 \mathrm{~h} \cdot \mathrm{week}^{-1}$, the equivalent of 2.6 full-time staff positions, was also reported.

In addition, there are currently 35 out-of-state subscribers who have the monthly releases automatically sent to their user identification codes when the files are uploaded to the HORT program.

Personnel for system maintenance consists of a technician in the Office of Consumer Horticulture who spends $\approx 10 \mathrm{~h} \cdot$ week $^{-1}$ handling files and developing material. The new material is reviewed and approved by extension specialists, who spend an estimated $2 \mathrm{~h} \cdot \mathrm{week}^{-1}$. This gives a total system/personnel time commitment equivalent to less than one-third of a full-time employee. 
Evaluation of other system components. The system has continued to grow over the 5 years since its inception, with each of the new components meeting different needs. As extension offices have added computers, the use by agents and Master Gardeners has increased. The computer automatically records use of the program. A check of this record $\approx 1$ year after the agent survey showed the HORT system is now used by individuals in $>100$ offices statewide.

The HORT system helps to keep extension agents' knowledge current by providing them with the latest information on consumer horticulture via a convenient reference source. Informational materials can be located easily and transferred in seconds. The suitability of the material for mass media use allows agents to produce quality programming in a minimum of time, and the range of information available allows agents to adapt the materials for use in any part of the state. Meeting statewide needs with low costs the HORT system ensures that agents have the resource: to provide extensive horticultural information to Virginia consumers. Individuals from other states wishing to receive the monthly releases can do so by sending a mail message containing the following line to the appropriate address:

SUBSCRIBE HORT-L JOHN DOE (replace with your name)

LISTSERV@V1VM1 (if you are at a BITNET node), or

LISTSERV@VTVM1.CC.VT.EDU (if you are at an Internet node)

To cancel the subscription, send the following message to one of the addresses shown above:

\section{SIGNOFF HORT-L}

At this time, there is no charge for subscribing to the HORT computer network. For more information on the other networks mentioned out-of-state requests can be directed to the following telephone numbers: CUFAN (803)656-5080; PENpages (814)863-3449; S.O.N. (517)355-9741 .

\section{Literature Cited}

Bufford, R. W. 1991. On-line.. information at your fingertips. Green Industry Today April:4-5.

Dewitt, C.A. 1988. CUFAN: system design and use. Proc. 2nd Intl. Conf. on Computers in Agr. Ext. Programs, Lake Buena Vista, Fla. 